\title{
Consideration of a Local Aluminum-Induced Crystallization Process Guided along the $\mu$-Holes Fabricated with fs Laser Pulses
}

\author{
Kwang H. OH*1, I. B. SOHN ${ }^{2}$ and S. Z. LEE \\ ${ }^{*}$ Laser Advanced System Industrialization Center, Jeonnam Technopark Stiftung \\ 329-3 Samtae-ri Nam-myeon Jangseong-gun Jeollanam-do, 515-893, Republic of Korea \\ E-mail: sharkie@jntp.orkr \\ ${ }^{2}$ Advanced Photonics Research Institute, Gwangju Institute of Science and Technology \\ 1 Oryong-dong Buk-gu Gwangju, 500-712, Republic of Korea
}

\begin{abstract}
A polycrystalline silicon (poly-Si) film is produced by the aluminum-induced crystallization (AIC) process guided along the $\mu \mathrm{m}$-sized laser hole and characterized for application to a seeding layer of poly-Si solar cells. We investigated the crystallization of amorphous silicon (a-Si) films using the AIC process with a structure of glass $/ \mathrm{Al} / \mathrm{SiO}_{2} / \mathrm{a}-\mathrm{Si}$ in which the silicon oxide $\left.(\mathrm{SiO})_{2}\right)$ layer has holes with $1 \sim 2 \mu \mathrm{m}$ in diameter so that the AIC process occurred only through the hole. The purpose of our experiment is to see the poly-Si grain growth, if possible, from a single poly-Si seed in the AIC process. For the experiment, the microhole array of about $1 \sim 2 \mu \mathrm{m}$ in diameter is prepared in the $\mathrm{SiO}_{2}$ layer of the structure using femtosecond laser pulses and the AIC process is carried out with the conventional heat treatment procedure. As results, it is observed that the crystallization of a-Si occurred only in the area under the microhole and the grain of poly-Si grew to the size of over $3 \mu \mathrm{m}$. Furthermore, it was shown that the grain grew with one dominant crystal orientation.
\end{abstract}

DOI: 10.2961/jlmn.2014.03.0016

Keywords: poly-Si, Al-induced crystallization (AIC), poly-Si solar cell, seeding layer, microhole

\section{Introduction}

Crystalline silicon-based thin-film solar cells, in recent, have been received attention as a promising alternative to the conventional bulk silicon solar cells due to its applicability of the inexpensive foreign substrates like glass [1-3]. For the fabrication of polycrystalline silicon (polySi) thin film solar cell, it is necessary to prepare for a good quality poly-Si thin film as a seeding layer on the glass substrate [4].

Among the various techniques to grow the crystalline silicon films on the glass substrate, aluminum-induced crystallization (AIC) process of amorphous silicon (a-Si) is an attractive candidate that could obtain a poly-Si seeding layer having the large size grains and preferential crystal orientation at a low temperature $[3,5]$.

In AIC process, the effect of native oxide layer at $\mathrm{Al} / \mathrm{a}$ $\mathrm{Si}$ interface as a key membrane on the poly-Si grain size and preferential crystal orientation is highly significant and thus several previous researches were reported the AIC process with this structure $[6,7]$.

Consequently the grain growth and the relevant crystal orientation are only analyzed experimentally on a large area $[8,9]$.

In fact, however, many local AIC processes occurred in the whole area and affect each other resulting poly-Si grain growth [10-12]. It is also interesting to see the grain growth by a local AIC process in a narrow area and the relevant crystal orientation.

If the local AIC processes could occur uniformly in the whole area, it could be obtained a large size grain and the relevant crystal orientation with the better probability and reproducibility.

In this paper, it is characterized that a poly-Si grain was formed by a local AIC process through a microhole fabricated with fs laser pulses. In addition, the influence of a thick $\mathrm{SiO}_{2}$ layer with the microhole array upon the crystallization of a-Si in the AIC process is demonstrated macroscopically.

\section{Experiments}

For the amicable AIC experiments, glass $/ \mathrm{Al} / \mathrm{SiO}_{2} / \mathrm{a}-\mathrm{Si}$ structures were prepared where an aluminum (Al) layer was deposited on glass substrate by a dc magnetron sputter, $\mathrm{SiO}_{2}$ and a-Si films by PECVD method as described in Fig. 1. A thin $\mathrm{Al}_{2} \mathrm{O}_{3}$ buffer layer between $\mathrm{Al}$ and $\mathrm{SiO}_{2}$ was natively oxidized in ambient atmosphere.

Prior to the deposition of a-Si film on the $\mathrm{SiO}_{2}$ layer, as shown in Fig. 2, a 30×30 microhole matrix with a very tiny diameter of approximately $1 \sim 2 \mu \mathrm{m}$ and a pitch of around $30 \mu \mathrm{m}$ was fabricated using the femtosecond laser pulses to induce the localized AIC process through the holes. In accordance with the previous research report [13], the periodic 3-D $\mathrm{SiO}_{2}$ holes structure has wide applications to reduction of surface reflectivity of the optical devices. The average depth of holes measured with atomic force microscope (AFM) was about $120 \mathrm{~nm}$. Also, the sample surface was not cleaned prior to the a-Si layer deposition in order to protect from the deformation and blockage of hole.

The annealing temperature was varied from 450 to $550^{\circ} \mathrm{C}$ whereas the sample heating was kept at the same 


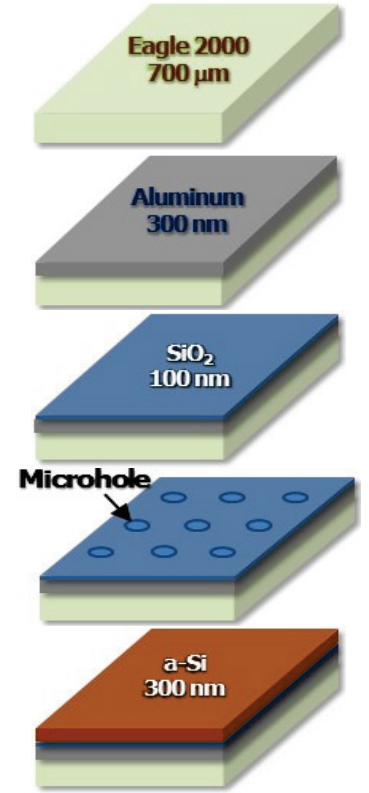

[Glass substrate]

- Ultrasonic cleaning

(Acetone+Ethanol)

- DI water rinse

[Metal layer deposition]

- Target : Al (5N)

- Thickness : $300 \mathrm{~nm}$

- Deposition : DC sputter

[Oxide layer deposition]

- Target : $\mathbf{S i O}_{2}$

- Thickness : $100 \mathrm{~nm}$

- Deposition : PECVD

[Microhole fabrication]

- Drill tool : fs laser

- Hole diameter : 1 2 $\mu \mathrm{m}$

- Hole pitch : $30 \mu \mathrm{m}$

[a-Si deposition]

$\cdot \mathrm{SiH}_{4}: \mathrm{H}_{2}=1: 5 \mathrm{sccm}$

- Thickness : $300 \mathrm{~nm}$

- Deposition : PECVD

Fig. 1 Process sequence for the sample preparation.

time of 2 hours regardless of temperature in the furnace of nitrogen circumstance. All annealing processes were monitored with the in-situ microscope. After annealing, the sample was cut by focused ion beam (FIB) milling near the hole in order to analyze the AIC result. The characteristics of AIC were closely examined by scanning electron microscope (SEM) and transmission electron microscope (TEM) with a cross-sectional profile of the prepared sample.

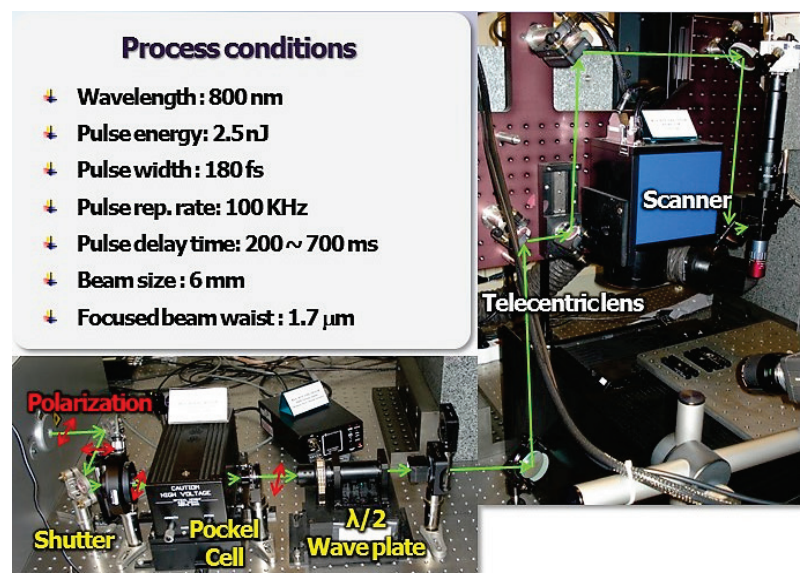

(a)

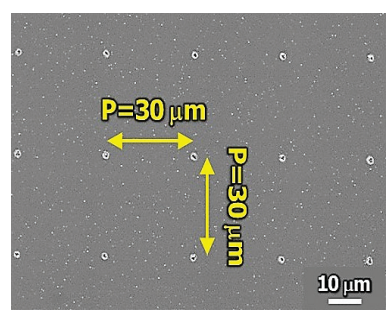

(b)

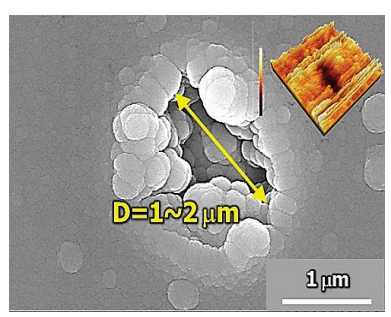

(c)
Fig. 2 (a) Image of the experimental setup for fabrication of the microhole array using fs laser pulses, (b) SEM image of microhole array with a diameter of $1 \sim 2 \mu \mathrm{m}$ and a pitch of 30 $\mu \mathrm{m}$ fabricated by fs laser pulses, (c) enlarged picture of a microhole in Fig. 2(a) (insert : AFM scan image of a microhole).
Table 1 Experimental procedure of the AIC process

\begin{tabular}{|c|c|}
\hline $\begin{array}{l}\text { Deposition } \\
\text { conditions }\end{array}$ & $\begin{array}{l}\text { - Substrate : Eagle } 2000 \text { (Corning glass) } \\
\text { - Aluminum layer : } 300 \mathrm{~nm} \text { using DC sputter } \\
\text { - Sputtering target : } \mathrm{Al}(5 \mathrm{~N}) \\
\text { - } \mathrm{Al}_{2} \mathrm{O}_{3} \text { layer : }<2 \mathrm{~nm} \text { exposure to ambient air } \\
\text { - } \mathrm{SiO}_{2} \text { layer }: 100 \mathrm{~nm} \text { using PECVD } \\
\text { - a-Si layer : } 300 \mathrm{~nm} \text { using PECVD }\end{array}$ \\
\hline $\begin{array}{l}\text { Microhole } \\
\text { fabrication }\end{array}$ & $\begin{array}{l}\text { - Hole : } 1 \sim 2 \mu \mathrm{m} \text { dia. using fs laser pulses } \\
\cdot \text { Pattern : distance of } 30 \mu \mathrm{m} \text { (center to center) }\end{array}$ \\
\hline $\begin{array}{l}\text { Annealing } \\
\text { conditions }\end{array}$ & $\begin{array}{l}\text { - Heating stage : LinKam, TMS } 94 \\
\text { - Flow gas }: \mathrm{N}_{2}, 20 \mathrm{sccm} \\
\text { - Process pressure }: \text { atmosphere a-Si layer } \\
\text { - Sample size }: 10 \times 10 \mathrm{~mm}^{2} \\
\text { - Annealing temperature }: 450,500,550^{\circ} \mathrm{C} \\
\text { - Annealing time }: 120 \mathrm{~min}\end{array}$ \\
\hline
\end{tabular}

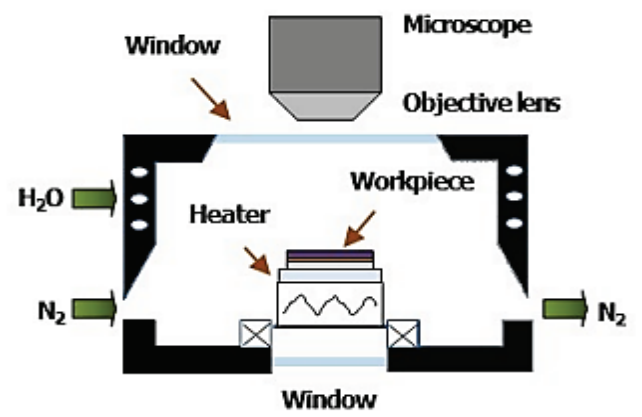

Fig. 3 A furnace system with the in-situ microscope for sample annealing.

Detailed sample preparation, the experimental condition and schematic diagram of the heating chamber are described in Table 1 and Fig. 3.

\section{Results and discussion}

\subsection{Scanning electron microscope (SEM) analysis}

As results of AIC process it can be seen that in the case without the microhole the thick $\mathrm{SiO}_{2}$ layer hinders the AIC process at the $\mathrm{Al} / \mathrm{a}-\mathrm{Si}$ interface and only the Al layer was expanded in volume (see Fig. 4(a)). And in the case with the microhole in Fig. 4(b), the AIC process is successfully carried out so that the diffused Al traces are seen on the surface of the top layer where the microhole is made only for the $\mathrm{SiO}_{2}$ layer (hole \#1). In the case of hole \#2, however, the hole is penetrated into the Al layer and the Al could not diffused though the hole into the upper a-Si layer, resulting no sufficient AIC process occurred. Figure 4(c) represents the enlarged cross-sectional profile of hole \#2 in Fig. 4(b). Figure 4(d) shows the crystallization of the a-Si under the area of the hole with a grain size of about $3 \sim 4$ $\mu \mathrm{m}$.

\subsection{Crystallization and preferential orientation}

In order to investigate the crystallization of a-Si and the preferential orientation of poly-Si grains, the $\mathrm{x}$-ray diffractometer (XRD) analysis was carried out with the samples annealed at 450,500 , and $550^{\circ} \mathrm{C}$ for 2 hours, respectively. At relatively low temperature of $450^{\circ} \mathrm{C}$, no $\mathrm{Si}$ 


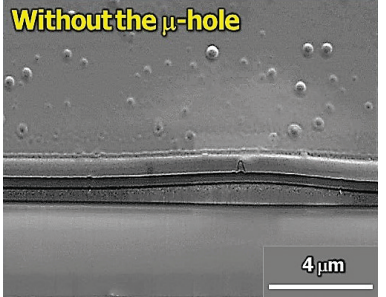

(a)

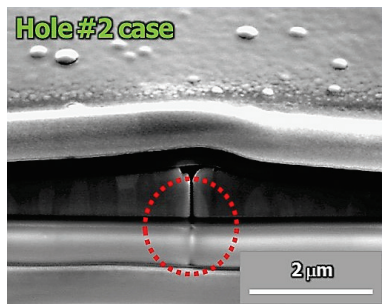

(c)

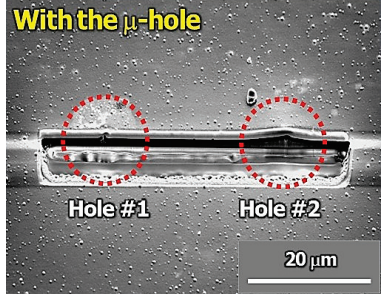

(b)

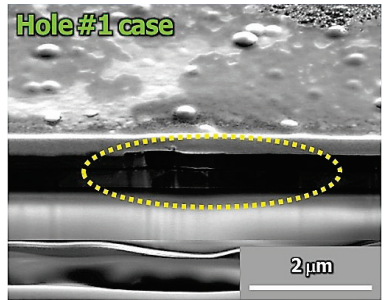

(d)
Fig. 4 SEM images of (a) cross-sectional profile of the structure without the hole after heat treatment, (b) cross-sectional profile of the structure with the holes after heat treatment : in the case of hole preparation in the $\mathrm{SiO}_{2}$ layer (hole \#1) and in the case of hole penetrated into the $\mathrm{Al}$ layer through the $\mathrm{SiO}_{2}$ layer (hole \#2), (c) the enlarged cross-sectional profile of a penetrated hole to Al layer and (d) the crystallization of the aSi under the area of the hole.

peak except for the crystal orientation of (202) was detected. As gradually elevated annealing temperature, the $\mathrm{Si}$ peak of several orientation are detected but Al crystal is still predominant.

Figure 5 shows the XRD data of poly-Si grain produced at relatively high temperature of $550^{\circ} \mathrm{C}$ for 2 hours. In our case, the crystallinity of poly-Si film with the dominant crystal orientation of (111) was assumed to $85 \%$ from XRD analysis as shown in Fig. 5.

\subsection{Degree of crystallization}

Regardless of the shape and diameter of the microhole fabricated with fs laser pulses, the crystallization of a-Si through the AIC process is fully achieved at a relatively high temperature of $550^{\circ} \mathrm{C}$ as can be seen from the Raman data of Fig. 6. From Fig. 6, the Si crystal peak of $520 \mathrm{~cm}^{-1}$ could be detected under all the microhole areas of the sample.

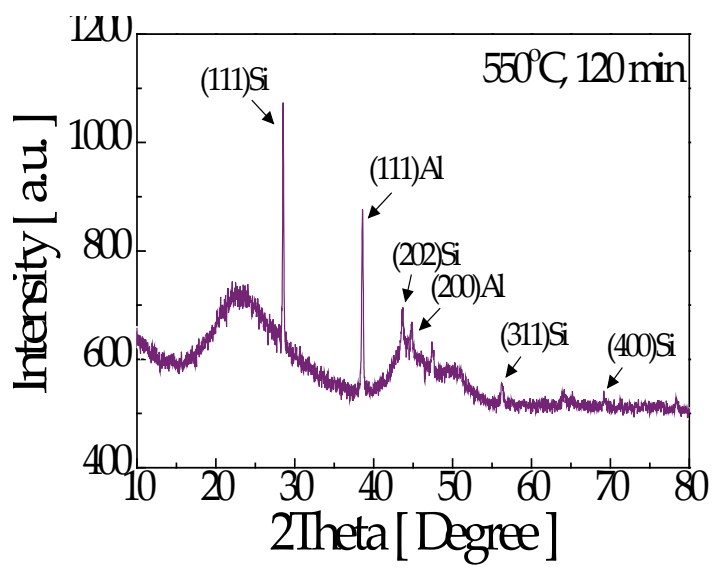

Fig. 5 XRD data of the poly-Si grain produced by the AIC process at the annealing conditions of $550^{\circ} \mathrm{C}$ and 2 hours.

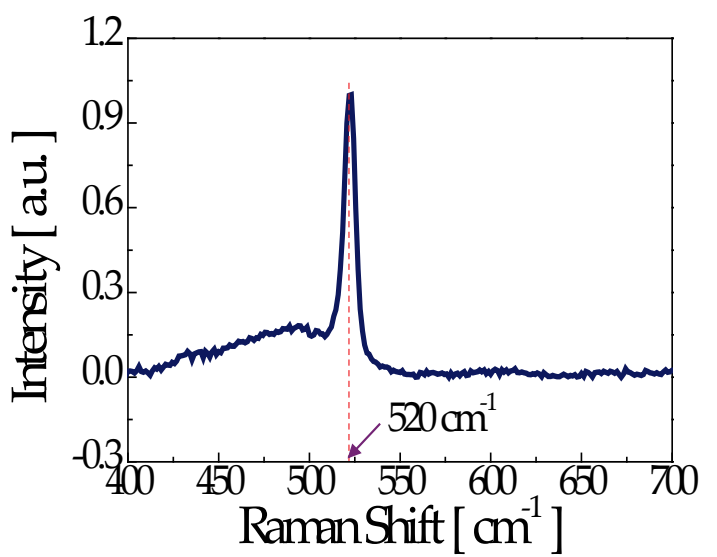

Fig. 6 Raman data of the poly-Si film produced by the AIC process with the microhole structure.

\subsection{Transmission electron microscope (TEM) analysis}

TEM sample is prepared around the marked area of the Fig. 4(d). As shown in the TEM image of Fig. 7(a), the sample was too thin for the focused ion beam (FIB) milling and as a result, partially drilled. However, in the rest area poly-Si was observed as shown in Fig. 7(a) and furthermore, Si grain has one dominant crystal orientation as represented in Figs 7(b) and 7(c), respectively.

To investigate the preferential crystal orientation, the diffraction ring pattern of poly-Si film was measured by TEM. As already verified in the TEM images, most of the poly-Si grains have Si (111) orientation as shown in Fig. 7(d).

\subsection{Energy dispersive spectrometer (EDS) analysis}

From the EDS spectrum profile of the TEM sample of Fig. 8(a), it can be assumed that the poly-Si grain is formed around the microhole center with a size of $\sim 500 \mathrm{~nm}$. As known in Fig .8(b), it is an obvious evidence that Si peak in

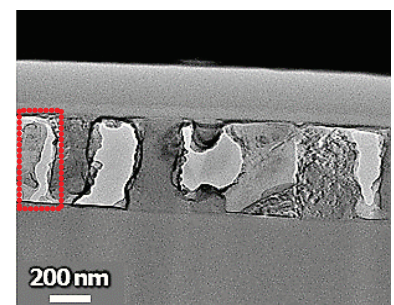

(a)

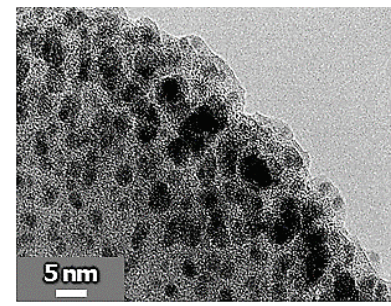

(c)

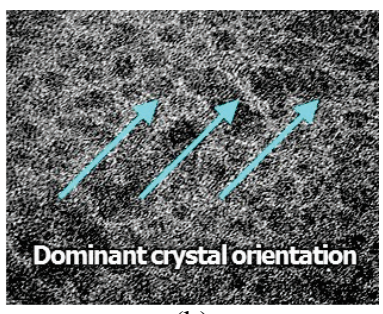

(b)

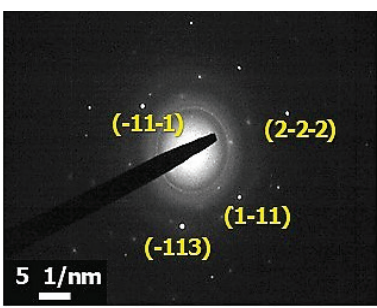

(d)
Fig. 7 TEM images of (a) cross-sectional profile of the structure as Fig. 4(d) and (b) the poly-Si film formed by the AIC process (magnification of the marked area (see dot line) of Fig. 7(a), $\times 590 \mathrm{k}$ ). (c) Enlarged TEM image of the marked area of Fig. 7(a) and (d) diffraction ring pattern of poly-Si produced by the AIC process only through the microhole. 


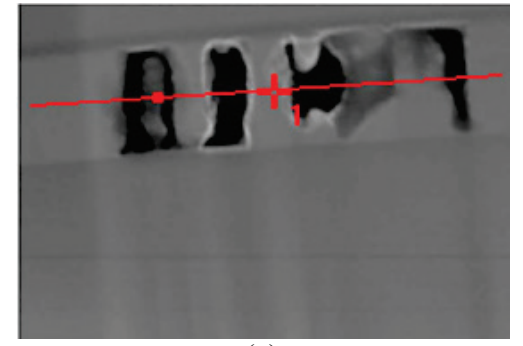

(a)

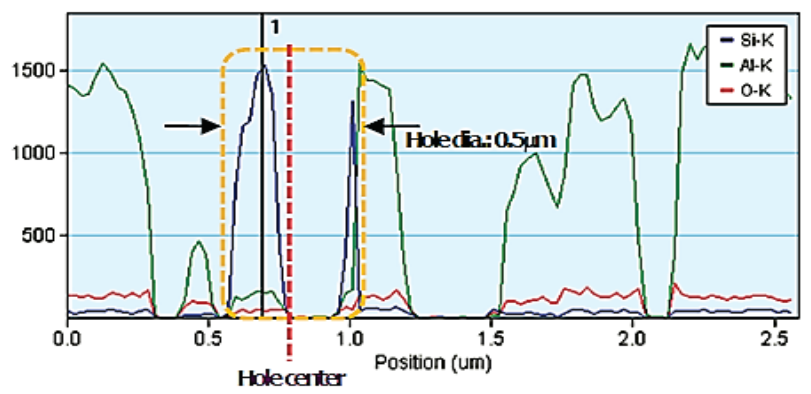

(b)

Fig. 8 EDS profiles of the TEM sample.

the EDS spectrum only appeared around the center of microhole, resulting in a poly-Si grain. The poly-Si grain spectrum is shown in the marked area with the dot lines in Fig. 8(b). Compared to the size of poly-Si grain in the SEM analysis, the grain size measured from the TEM sample was smaller than that from the SEM sample as can be seen in Fig. 8(b).

The schematic diagram of the formed poly-Si grain, TEM and SEM samples is shown in Fig. 9.

It is assumed that the samples for the SEM and TEM analyses are prepared as represented in Fig. 9, so that the grain sizes of the samples are different. The sample for SEM indicates around the edge of the hole, whereas the sample for TEM around the edge of the grain. However, several hundred nanometers readily wandered from the microhole edge whenever the sample are prepared for measurement and eventually the fabricated sample has a different size as mentioned previously.

From such assumption, the results of the different grain size can be relevant to each other. And we assume that the cylindrical poly-Si grain is formed with the maximum size of $4 \mu \mathrm{m}$.

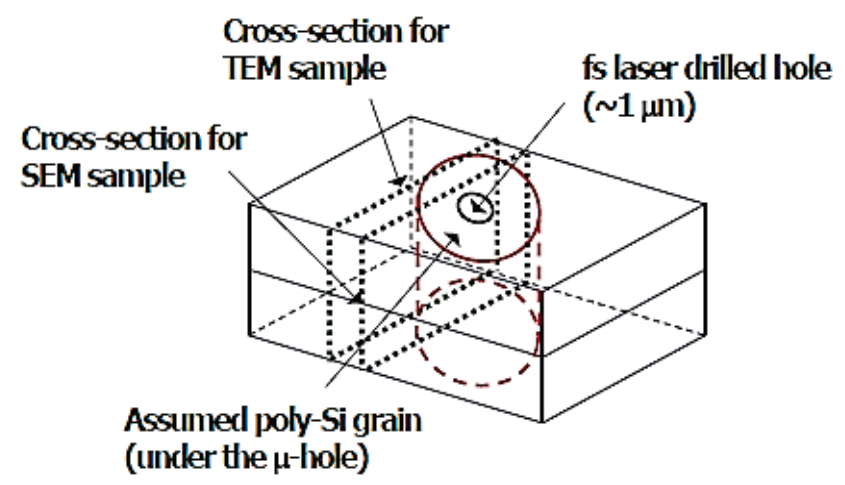

Fig. 9 The sample preparation methods for SEM and TEM analyses, respectively.

\section{Summary}

In summary, we have investigated the crystallization of a-Si films using the AIC process with the glass $/ \mathrm{Al} / \mathrm{SiO}_{2} / \mathrm{a}-$ $\mathrm{Si}$ sample. In the structure with the $\mathrm{SiO}_{2}$ layer as a buffer, crystallization of the a-Si was induced only through a microhole and as results, the poly-Si grain with a size of 3 $\sim 4 \mu \mathrm{m}$ can be obtained.

A local AIC process guided along the $\mu \mathrm{m}$-sized hole could not form much larger grain than the size of the hole. Therefore, for the formation of a larger grain, small crystals from many local poly-Si seeds should be combined and laterally grown.

\section{Acknowledgments}

This work was supported by the Industrial Technology Research Infrastructure Program (N0000012, Infrastructure establishment on the laser processing system for the next generation micro applications) funded by the Ministry of Trade, Industry and Energy (MOTIE, Republic of Korea).

\section{References}

[1] K. Yamamoto, M. Yoshimi, Y. Tawada, Y. Okamoto, A. Nakajima and S. Igari : Appl. Phys. A, 69, (1999) 179.

[2] M. J. McCann, K. R. Catchpole, K. J. Weber and A. W. Blakers : Sol. Energy Mater. Sol. Cells, 68, (2001) 173.

[3] H. Kuraseko, N. Orita, H. Koaizawa and M. Kondo : Appl. Phys. Express, 2, (2009) 015501.

[4] O. Nast and A. J. Hartmann : J. Appl. Phys., 88, (2000) 716.

[5] Y. Sugimoto, N. Takata, T. Hirota, K. Ikeda, F. Yoshida, H. Nakashima and H. Nakashima: J. J. Appl. Phys., 44, (2005) 4770.

[6] H. Kim, D. Kim, G. Lee, D. Kim and S. H. Lee : Sol. Energy Mater. Sol. Cells, 74, (2002) 323.

[7] Y. H. Zhao, J. Y. Wang and E. J. Mittemeijer : Appl. Phys. A, 79, (2004) 681.

[8] A. Sarikov, J. Schneider, M. Muske, I. Sieber and S. Gall : Thin Solid Films, 515, (2007) 7465.

[9] I. Sieber, J. Schneider, I. Doerfel, P. Schubert-Bischoff, S. Gall and W. Fuhs : Thin Solid Films, 427, (2003) 298.

[10] O. Nast, T. Puzzer, L. M. Koschier, A. B. Sproul and S. R. Wenham : Appl. Phys. Lett., 73, (1998) 3214.

[11] G. J. Qi, S. Zhang, T. T. Tang, J. F. Li, X. W. Sun and X. T. Zeng : Surf. Coat. Technol., 198, (2005) 300.

[12]D. He, J. Y. Wang and E. J. Mittemeijer : Scripta Mater., 54, (2006) 559.

[13] J. Yang, F. Luo, T. S. Kao, X. Li, G. W. Ho, J. Teng, X. Luo and M. Hong : Light-Sci. Appl., 3, (2014) e185.

(Received: June 15, 2014, Accepted: November 11, 2014) 